\title{
New Records and Potential Distribution of the Ant Gracilidris pombero Wild \& Cuezzo (Hymenoptera: Formicidae)
}

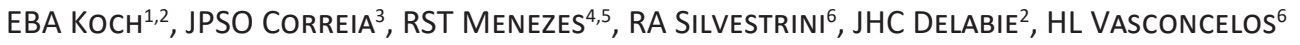 \\ 1 - Universidade Federal da Bahia, Programa de Pós-graduação em Ecologia e Biomonitoramento, Salvador-BA, Brazil \\ 2 - Laboratório de Mirmecologia, Centro de Pesquisas do Cacau - Comissão Executiva Plano da Lavoura Cacaueira, Ilhéus-BA, Brazil \\ 3 - Fundação Oswaldo Cruz, Instituto Oswaldo Cruz, Programa de Pós-graduação em Biodiversidade e Saúde, Rio de Janeiro-RJ, Brazil \\ 4 - Department of Entomology, National Museum of Natural History, Smithsonian Institution, Washington-DC, USA \\ 5 - Departamento de Biologia, Faculdade de Filosofia, Ciências e Letras - Universidade de São Paulo (FFCLRP/USP), Ribeirão Preto-SP, Brazil \\ 6 - Instituto de Biologia, Universidade Federal de Uberlândia, Uberlândia-MG, Brazil
}

\section{Article History}

\section{Edited by}

Gilberto M. M. Santos, UEFS - Brazil

Received

12 December 2017

Initial acceptance 30 May 2018

Final acceptance 19 July 2018

Publication date 01 October 2018

\section{Keywords}

Biogeography, Dolichoderinae, GARP, Maxent, Neotropical Region.

\section{Corresponding author}

Elmo Borges de Azevedo Koch

Instituto de Biologia

Programa de Pós-graduação em Ecologia

e Biomonitoramento

Rua Barão de Geremoabo, 147, Ondina

CEP 40170-290, Salvador-BA, Brasil.

E-Mail: elmoborges@gmail.com
Universidade Federal da Bahia

\begin{abstract}
Gracilidris pombero Wild \& Cuezzo, 2006 is an ant that remains poorly studied. Endemic from South America, its geographical distribution is known from few and scattered collection points. In this study, we present new occurrence records of $G$. pombero obtained through extensive collections along the Cerrado biome and the Atlantic Forest of northeastern Brazil. Based on the new and existing occurrence records we produced a model of the geographic distribution of $G$. pombero. Modelling method was chosen based on maximization of model performance after evaluating a series of modelling approaches, including different parametrizations of the Maxent algorithm and distinct runs of the GARP algorithm. We found a total of 43 new records of G. pombero in Brazil, including the first records of this species in the states of Goiás, Mato Grosso do Sul, Piauí, Sergipe and Tocantins. Based on our model, the areas of highest suitability of occurrence of $G$. pombero are located in two main zones in South America: one ranging from midwestern Brazil to southeastern Bolivia and Paraguay; and the other spanning the south of Brazil and Uruguay.
\end{abstract}

\section{Introduction}

Gracilidris pombero Wild \& Cuezzo, 2006 is the only extant species of the Dolichoderinae ant genus Gracilidris Wild \& Cuezzo, 2006. The natural history of this species is poorly known but previous studies indicate that colonies are relatively small (Wild \& Cuezzo, 2006). This ant builds its nest in the ground, and foraging is predominantly or strictly nocturnal, which may explain why G. pombero is poorly represented in entomological collections (Wild \& Cuezzo, 2006).

The species was described based on workers collected in a few localities in Paraguay, Argentina and the central and northeastern regions of Brazil (Wild \& Cuezzo, 2006; Guerrero \& Sanabria, 2011). More recently, G. pombero was found in the extreme south of Brazil, extending its previous known latitudinal range by about $450 \mathrm{~km}$ to the south (Feitosa et al., 2015). Gracilidris pombero seems to be associated with relatively dry and open habitats, such as grasslands and savannas (Wild \& Cuezzo, 2006; Feitosa et al., 2015). However, populations of this species have also been found in the Colombian Amazon and in the Atlantic Forest of northeastern Brazil. Nevertheless, in both cases, the ants were not found in forest areas, but rather in human-managed habitats (such as cattle pastures or cocoa plantations) (Wild \& Cuezzo, 2006; Guerrero \& Sanabria, 2011).

Based on the known distribution of the living species (G. pombero), and a fossil from the Dominican amber [Gracilidris humilioides (Wilson, 1985)], Guerrero \& 
Sanabria (2011) proposed that during drier periods of the Pleistocene Gracilidirs occurred from Paraguay to Puerto Rico (including the Amazon), but as the climate became wet again during the Holocene, its distribution retracted, resulting in the isolation of populations in the Colombian Amazon. The same hypothesis may also explain the occurrence of $G$. pombero in the Brazilian Atlantic Forest biome. Assuming that $G$. pombero was once much more widely distributed, it is more likely that the Atlantic Forest populations represent relictual populations rather than populations that recently expanded into that region as the result of land cover and land use changes (Guerrero \& Sanabria, 2011).

In this study, we present new occurrence records of $G$. pombero obtained through extensive collections of grounddwelling ants along the Cerrado biome (South American savanna) of central Brazil and along the Atlantic Forest of northeastern Brazil. Based on the new and published information we produced a model of the potential geographic distribution of G. pombero in order to identify areas where new discoveries are more likely, and to determine the main climatic variables that help to explain the current distribution of the species.

\section{Materials and methods}

\section{Occurrence records}

Part of the new records of G. pombero presented here come from standardized sampling of the ant fauna conducted in 29 well-preserved savanna sites using pitfall traps (Vasconcelos et al., 2018). These sites were distributed across the entire extension of the Brazilian Cerrado biome, in a region spanning ca. $20^{\circ}$ of latitude and $18^{\circ}$ of longitude (Vasconcelos et al., 2018).

Records recently published (Santos et al., 2017) obtained from ant surveys performed in several landscapes in the Atlantic Forest biome of the state of Bahia, Brazil, were also included in our analysis. In addition, we examined material deposited in the collection of the Laboratorio de Mirmecologia in the Centro de Pesquisa do Cacau - CEPEC/ CEPLAC (CPDC) (Ilhéus, Bahia, Brazil), and which include specimens collected in the Cerrado and Pampas biomes, cocoa plantations, or urban areas. Finally, we compiled all published records of occurrence of $G$. pombero through a detailed survey of the literature (Wild \& Cuezzo, 2006; Guerro \& Sanabria, 2011; Brandão et al., 2011; Neves et al., 2013; Costa-Milanez et al., 2014; Camacho \& Vasconcelos, 2015; Feitosa et al., 2015; Meurer et al., 2015; Solar et al., 2016).

\section{Ecological niche modeling (ENM)}

The distribution probability map of G. pombero was obtained by applying a filtered data set of the occurrence points on several bioclimatic variable layers from the WorldClim database (Hijmans et al., 2005). The modelling method was chosen based on maximization of model performance. This was done after evaluating a series of modelling approaches, including different parametrizations of the Maxent algorithm (using Maxent software version 3.4.1) and distinct runs of the Genetic Algorithm for Rule Set Production (GARP) (available in the openModeller software v1.1.0; Muñoz et al., 2009). We chose to work with the Maxent and GARP algorithms due to their superior ability and better performance even with a small data set in comparison with other modelling methods (Wisz et al., 2008). These algorithms have shown success to modeling distributions of several species using occurrence records and environmental data (Peterson et al., 1999; Anderson et al., 2003; Raimundo et al., 2007; Zhang et al., 2015). Additionally, we used the AUC (Average Area under Curve) and sensitivity values to test the performance of our models. Both AUC and sensitivity values ranges from 0 to 1 , where a score higher than 0.9 can be considered good predictors of favorable conditions for the occurrence of a species (Phillips et al., 2006).

Data filtering of the 57 available occurrences (see Table 1) was necessary to avoid biased probability estimations (Kramer-Schadt et al., 2013; Boria et al., 2014), since it was observed a spatial aggregation pattern along the map, as a result of intense sampling efforts within some specific regions. Filtering criteria was based on distance between points: for a given group of neighboring occurrences whose distance between one another was less than $2 \mathrm{~km}$, only the central point was maintained. Hence, the filtered data set consisted of 33 occurrence points, which were divided into calibration (27) and validation (6) in order to allow an independent and robust validation. The calibration data were used as the only occurrences available to perform the modeling process, whereas the validation data were considered for validation purposes only.

In order to obtain a consistent model, we evaluated the degree of correlation between the bioclimatic variables based on Principal Component Analysis (PCA), using the software PAST v3.02 (Hammer et al., 2001) as performed by Menezes et al. (2017). Thus, we extracted values of each occurrence point associated to each of the 19 bioclimatic layers using Quantum-GIS v2.8 (Open Source Geospatial Foundation Project, Beaverton, OR, USA) and we checked autocorrelated variables by PCA. Simultaneously, we verified the percent of contribution of each bioclimatic layer and we excluded some non-contributing variables. Finally, from the 19 bioclimatic variables available, only 16 were passed into model algorithms either because of high correlation or due to absence of contribution for our species distribution modelling.

The 27 occurrence calibration points and the 16 bioclimatic variables were passed to several maxent and GARP algorithms, with different parameters. The resultant simulated distributions consisted of two Maxent distributions surfaces and three probability distributions from GARP. The best model was chosen based on the maximization of calibration and validation sensitivity values. Validation was performed by calculating the percentage of validation points located in high probability areas. The final model consisted 
of Maxent algorithm run with the following parameters: quadratic, product, threshold and hinge, 500 iterations, regularization multiplier equal 1 , thirty percent of random test and ten replicates subsampled. All modelling procedures were developed for the Neotropical Region at a spatial resolution of $2.5^{\circ}$.

\section{Results}

New occurrence records

We found 43 new records of G. pombero for Brazil, including the first records of this species for the states of Goiás, Mato Grosso do Sul, Piauí, Sergipe and Tocantins (Table 1). Nevertheless, most of the new records were largely coincident or complementary to the previous known range of G. pombero in South America. Among the new records, most $(70 \%)$ were obtained in typical Cerrado vegetation (savanna-like vegetation), 18.5\% in agricultural systems (cocoa plantations and small-scale agriculture) or pastures, $7 \%$ in the Atlantic Forest biome (fragments with low forest cover and in its surrounding matrix in some cases), $2.3 \%$ in urban areas (e.g., university campus), and $2.3 \%$ in an abandoned mining area in the south of Brazil (see Table 1).

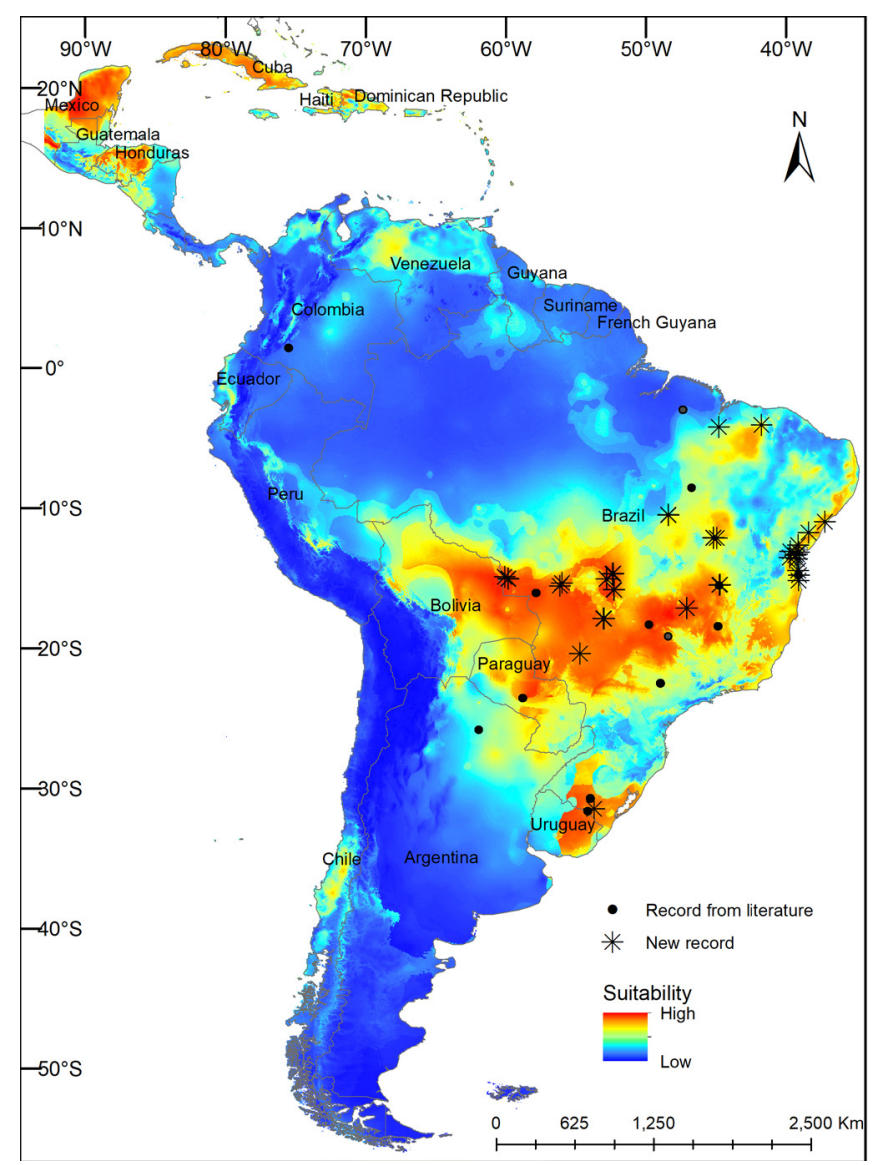

Fig 1. Potential geographical distribution of Gracilidris pombero in the Neotropical Region. The intensity of color gradient from blue to red (the redder color means the higher probability of occurrence) is proportional to probability of occurrence.
ENM using Maxent

The performance analysis of the geographic distribution for $G$. pombero, obtained through the best-fit Maxent model, showed high accuracy values, as demonstrated by both AUC and sensitivity metrics. AUC values ranged from 0.92 for calibration dataset and 0.88 for validation data, while sensitivity varied from 0.85 for the calibration and 0.83 considering validation. The small variation observed between calibration and validation performance metrics shows model's ability to predict with high accuracy even in areas in which occurrence points were not available for model fitting, indicating a high degree of confidence on the predicted distribution.

The areas of highest suitability for the occurrence of $G$. pombero were located in two main zones in South America: one ranging from midwestern Brazil to southeastern Bolivia and Paraguay; and the other spanning the south of Brazil and Uruguay (Fig 1). Among these places, for Uruguay and Bolivia have not been registered any occurrence of the species yet. Other suitable regions include the coast of Northeastern Brazil. Moreover, the model predicted high suitability for the occurrence of G. pombero also in Central America, notably in the south of Mexico, Cuba, Honduras, and the Dominican Republic, indicating that the entire region has climatic conditions suitable for the species.

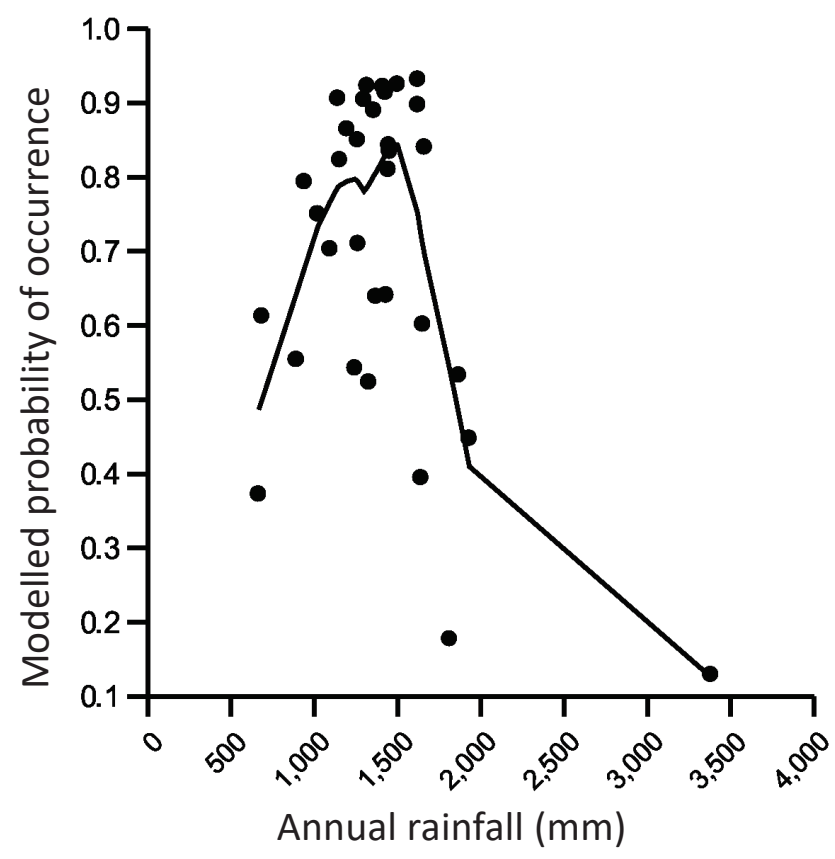

Fig 2. Modelled probability of occurrence of Gracilidris pombero in relation to annual rainfall. The line represents a scatterplot smoothing of the data.

Suitable areas were mainly guided by three variables in the model, which alone explained $83 \%$ of model prediction: annual precipitation $(42.6 \%)$, mean temperature of driest quarter (21.4\%), and temperature seasonality (18.8\%). Furthermore, the model indicates that sites receiving 1,000 to $1,500 \mathrm{~mm}$ of rain per year have the highest probability of occurrence of G. pombero (see Fig 2). 


\section{Discussion}

Our study represents a four-fold increase in the number of distributional records of G. pombero, from 14 to 57 records. We recorded G. pombero in eight Brazilian states, of which five (Goiás, Mato Grosso do Sul, Piauí, Sergipe and Tocantins) have the ant recorded for the first time. Over half of the new records (26 out of 43) were obtained during collections along the Brazilian Cerrado biome and more specifically in cerrado vegetation in biological reserves (Vasconcelos et al., 2018). Most of the remaining records were in eastern Bahia, within the Atlantic forest domain, were it was found in Atlantic Forest fragments of low forest cover and in human-managed habitats, including cattle pastures, cocoa plantations and other small-scale agriculture systems. One record corresponds to an urban area (university campus) in Sergipe. Similarly, the only new record in southern Brazil (Rio Grande do Sul) was in a human-disturbed area (an abandoned mine). These data reinforce the idea that $G$. pombero is a species typical of savannas, shrublands and grasslands, which nevertheless can also be found in disturbed habitats, such as forest edges, pasture, crops and urban areas.

Despite the limited information about the ecology and other specific aspects of the biology of G. pombero, we suggest that the large number of new records presented in this study is related to the sampling method used, since most of these records came from pitfall traps (Bestelmeyer et al., 2000), which collect ants with both diurnal and nocturnal habits. G. pombero is thought to exhibit nocturnal habits (Wild \& Cuezzo, 2006), and this may help to explain the difficulty of collecting it when using other sampling methods, such as visual searches, baits and Winkler traps. It is difficult to find the species even when performing more elaborate soil searches (depths up to $10 \mathrm{~cm}$ ) if they are carried out during daytime (Guerrero \& Sanabria, 2012).

Our distribution modelling suggests that although $G$. pombero has not been collected in Bolivia, it is very likely to be present there. Similarly, there is a strong chance of occurrence of $G$. pombero in northern Uruguay. The areas with highest probability of occurrence of G. pombero correspond largely with the distribution of the Cerrado, Chaco, and Pampa biomes of South America. Although G. pombero has been recorded several times in the Atlantic Forest, it was always found in relatively open forest sites (three cases; Table 1) or in non-forest habitats, particularly in cocoa plantations and urban areas, reinforcing the view that this species can tolerate some degree of anthropic disturbance (Guerrero \& Sanabria, 2011; Feitosa et al., 2015). The expansion of G. pombero to areas of this biome may be related to the historic impact of land use change by deforestation, with the replacement of native forests by agriculture or urban centers, intensified principally during the nineteenth and twentieth centuries (Young, 2003) and which continues - at an estimated rate of 29,075 ha deforested per year (SOS Mata Atlântica and INPE, 2017) - to date. The Brazilian Atlantic Forest currently accounts for about $11.6 \%$ of its original vegetative cover (Ribeiro et al., 2009), in a highly fragmented state with more than $80 \%$ of these fragments having an area of less than 50 ha (Ribeiro et al., 2011) surrounded by a matrix that can be pasture, agriculture, eucalypt plantations, or urban areas (Joly et al., 2014).

Interestingly, our model indicates a low probability of occurrence of G. pombero in the Caatinga, even though this biome is part of the "diagonal of dry biomes", which also includes the Cerrado and Chaco. In fact, several studies have failed to record this species in the Caatinga (Leal et al., 2003; Ulyssea \& Brandrão, 2013; Silva \& Delabie, 2014). This biome is drier than the Cerrado and Chaco and, as our model suggests, the probability of occurrence of $G$. pombero declines sharply at relatively dry regions with an annual rainfall of less than $1,000 \mathrm{~mm}$, such as in Caatinga (Ab'Saber, 1993).

Finally, the climatic conditions in Central America seem highly suitable for the occurrence of $G$. pombero although the ant seems totally absent from this region. This finding plus the Gracilidris Dominican fossil suggests that the genus Gracilidris, in the past, could have occurred both in Central and South America as shown by the known records of the genus (Guerrero \& Sanabria, 2011). A similar pattern is suggested for other dolichoderine genera such as Technomyrmex and Bothriomyrmex with a putative wide geographic distribution in the past but currently restricted to a few isolated forests (Fernandez \& Guerrero, 2008). However, further studies exploring the biogeographic history and the divergence time of Gracilidris will be necessary to elucidate the geographic origin of the genus.

\section{Acknowledgments}

Records of G. pombero presented here come from surveys conducted with financial support from the projects "Rede de Pesquisa Biota do Cerrado (RPB cerrado 6) Isoptera e Hymenoptera"; "Efeito da redução da cobertura vegetal e do histórico biogeográfico sobre limiares de extinção: um estudo multi-táxon na Mata Atlântica da Bahia"; and "Projeto Integrando Níveis de Organização em Modelos Ecológicos Preditivos" (INOMEP/PRONEXFAPESB-CNPQ).

EBAK is thankful to Bahia Research Foundation (FAPESB) by grant $0483 / 2015$. JPSOC is thankful to Conselho Nacional de Desenvolvimento Científico e Tecnológico (CNPq). RSTM is grateful to São Paulo Research Foundation (FAPESP) by grants 2015/02432-0 and 2016/21098-7. JHCD acknowledges his research grant from CNPq. We thank Fernando Fernández and Rodrigo Feitosa for assisting in the identification of the individuals of $G$. pombero deposited in the entomological collections at the Museu de Biodiversidade do Cerrado (MBC). 
Table 1. Records of Gracilidris pombero in the South America. LT = Literature data; SC = Data of scientific collection (CPDC*); $\mathrm{PD}=$ Project data**.

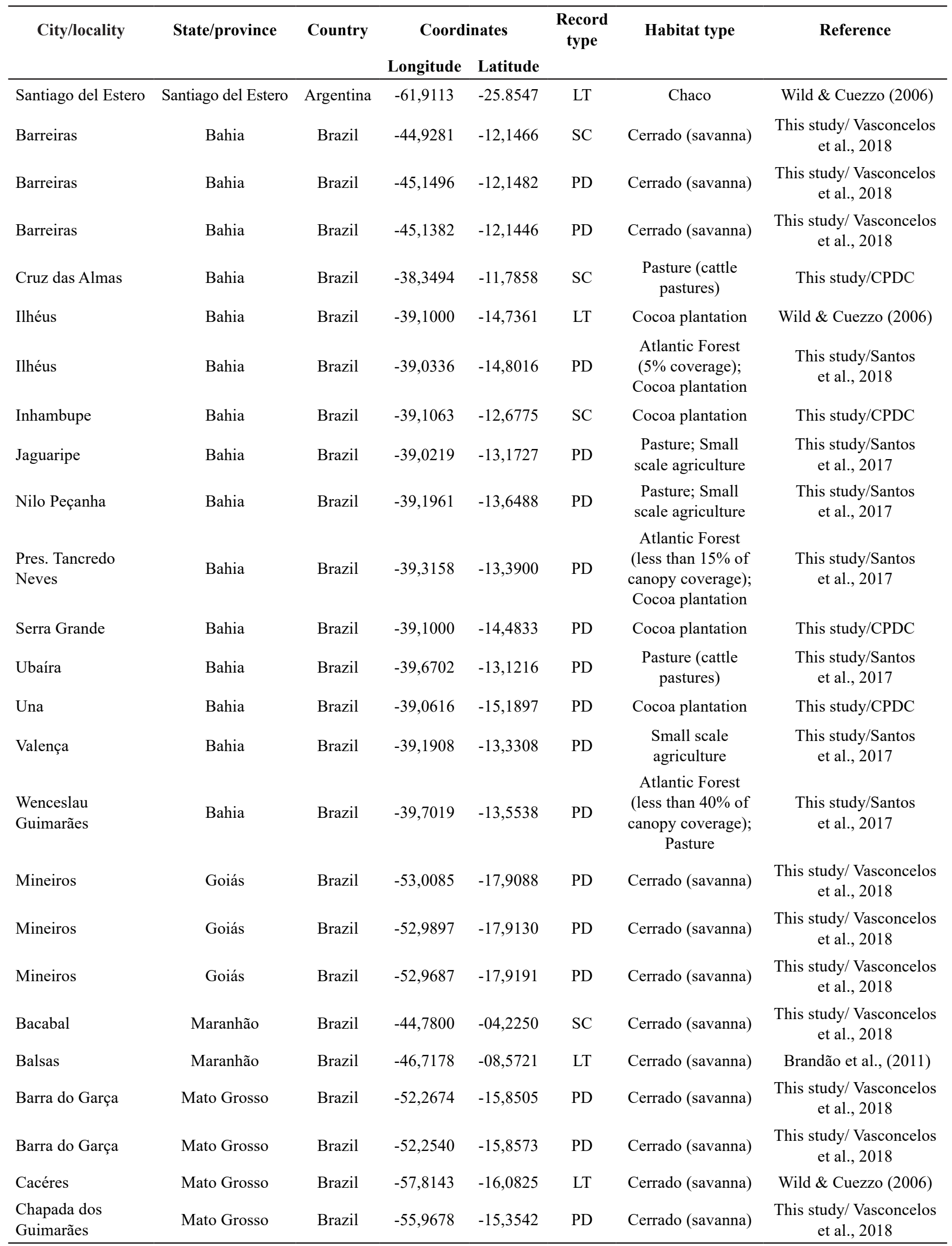


Table 1. Records of Gracilidris pombero in the South America. LT = Literature data; SC = Data of scientific collection (CPDC*); $\mathrm{PD}=$ Project data**. (Continuation)

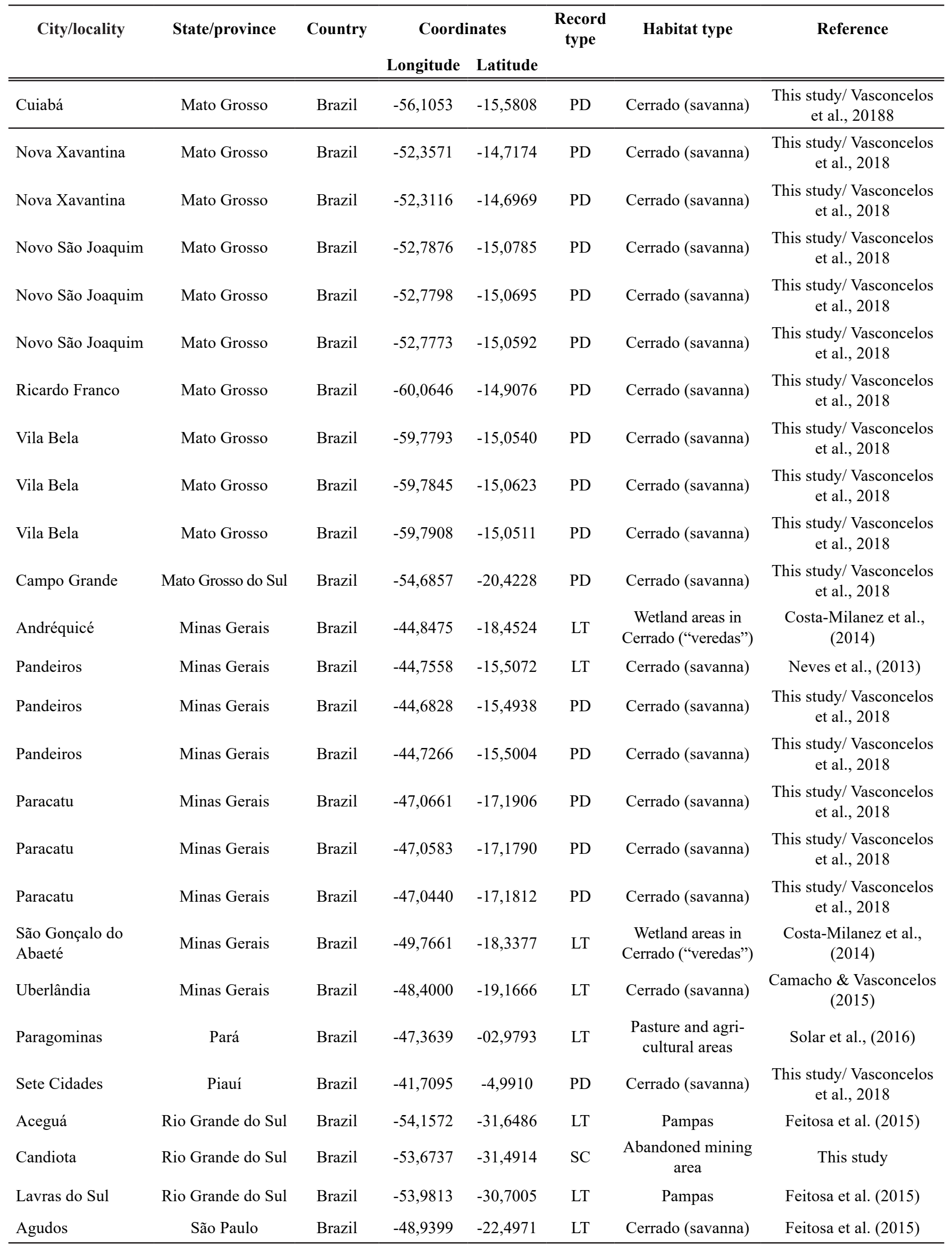


Table 1. Records of Gracilidris pombero in the South America. LT = Literature data; SC = Data of scientific collection (CPDC*); $\mathrm{PD}=$ Project data**. (Continuation)

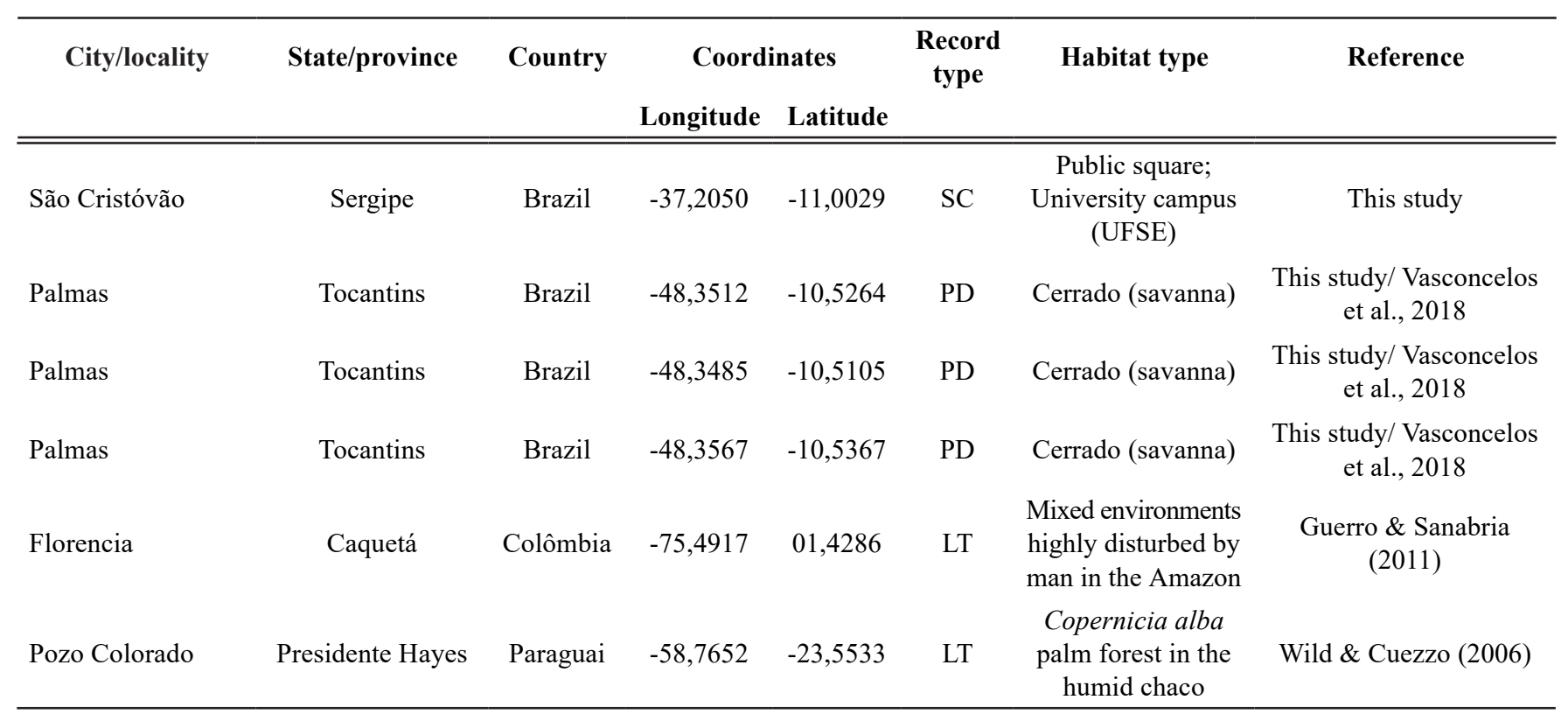

*CPDC $=$ Centro de Pesquisas do Cacau, Comissão Executiva do Plano de Lavoura Cacaueira (CEPLAC), Itabuna, Bahia, Brazil; **See acknowledgments section.

\section{References}

Ab’Saber, A.N. (Eds.). 2003. Os domínios da natureza no Brasil: potencialidades paisagísticas. São Paulo, Ateliê Editorial, 160 p.

Anderson, R.P., Lew, D. \& Peterson, A.T. (2003). Evaluating predictive models of species' distributions: criteria for selecting optimal models. Ecological Modelling, 162: 211-232.

Brandão, C.R.F., Silva, R.R. \& Feitosa, R.M. (2011). Cerrado ground-dwelling ants (Hymenoptera: Formicidae) as indicators of edge effects. Zoologia, 28: 379-387. doi: $10.1590 /$ S1984-46702011000300012

Bestelmeyer, B.T., Agosti, D., Alonso, L.E., Brandão, C.R.F., Brown Jr, W.L., Delabie, J.H.C. \& Silvestre, R. (2000). Field techniques for the study of ground-living ants: an overview, description, and evaluation. In Agosti, D., Majer, J.D., Alonso, L.E. \& Schultz, T.R. (Eds.), Ants: Standart Methods for Measuring and Monitoring Biodiversity (pp. 122-144). Smithsonian Institution, Washington, USA, 280p.

Boria, R.A., Olson, L.E., Goodman, S. M. \& Anderson, R.P. (2014). Spatial filtering to reduce sampling bias can improve the performance of ecological niche models, Ecological Modelling, 275: 73-77. doi: 10.1016/j.ecolmodel.2013.12.012

Camacho G.P. \& Vasconcelos, H.L. (2015). Ants of the Panga Ecological Station, a cerrado reserve in Central Brazil. Sociobiology, 62: 281-295. doi: 10.13102/sociobiology.v62i2. 281-2957

Costa-Milanez, C.B., Lourenço-Silva, G., Castro, P.T.A., Majer, J.D. \& Ribeiro, S.P. (2014). Are ant assemblages of Brazilian veredas characterized by location or habitat type? Brazilian Journal of Biology, 74: 89-99. doi: 10.1590/1519-6984.17612
Feitosa, R.M., Drose, W., Podgaiski, L.R. \& Medonça Jr., M.S. (2015). first record of the dolichoderine ant genus Gracilidris Wild \& Cuezzo (Hymenoptera: Formicidae) from Southern Brazil. Sociobiology, 62: 296-299. doi: 10.13102/ sociobiology.v62i2.296-299

Fernandéz, F. \& Guerrero, R.J. 2008. Technomyrmex (Formicidae: Dolichoderinae) in the New World: synopsis and description of a new species. Revista Colombiana de Entomología, 34: 110-115.

Guerrero, R.J. \& Sanabria, C. (2011). The first record of the genus Gracilidris (Hymenoptera: Formicidae: Dolichoderinae) from Colombia. Revista Colombiana de Entomología, 37: 159-161.

Guénard, B., Weiser, M.D. \& Dunn, R.R. (2012). Global models of ant diversity suggest regions where new discoveries are most likely are under disproportionate deforestation threat. PNAS, 109: 7368-7373. doi.org/10.1073/pnas.1113867109

Hammer, Z., Harper, D.A.T. \& Ryan, P.D. (2001). PAST: Paleontological statistics software package for education and data analysis. Palaeontologia Electronica, 4: 1-9.

Hijmans, R.J., Cameron, S.E., Parra, J.L., Jones, P.G. \& Jarvis, A. (2005) Very high resolution interpolated climate surfaces for global land areas. International Journal of Climatology, 25: 1965-1978. doi.org/10.1002/joc. 127

Hijmans, R.J. \& Graham, C.H. (2006). The ability of climate envelope models to predict the effect of climate change on species distributions. Global Change Biology, 12: 2272-2281. doi: 10.1111/j.1365-2486.2006.01256.x

Joly C., Metzger J.P. \& Tabarelli M. (2014) Experiences from the Brazilian Atlantic Forest: ecological findings and 
conservation initiatives. New Phytologist, 204: 459-473. doi: 10.1111/nph.12989

Kramer-Schadt, S., Niedballa, J., Pilgrim, J. D., et al. (2013) The importance of correcting for sampling bias in MaxEnt species distribution models. Diversity and Distributions, 19: 1366-1379. doi: 10.1111/ddi.12096

Leal, I.R. (2003). Diversidade de formigas em diferentes unidades de paisagem da Caatinga. In: Leal, I. R., Tabarelli, M. \& Silva J.M.C. (Eds.), Ecologia e Conservação da Caatinga, v.1. Recife: Editora Universitária UFPE, p. 435-461.

Menezes, R.S.T., Brady, S.G., Carvalho, A.F., Del Lama, M.A. \& Costa, M.A. (2017). The roles of barriers, refugia, and chromosomal clines underlying diversification in Atlantic Forest social wasps. Scientific Reports, 7: 7689. doi: 10.1038/ s41598-017-07776-7

Meurer, E., Battirola, L.D., Delabie, J.C.H. \& Marques, M.I. (2015). Influence of the vegetation mosaic on ant (Formicidae: Hymenoptera) distributions in the Northern Brazilian Pantanal. Sociobiology, 62: 382-388. doi: 10.13102/sociobiology.v62i3.359

Muñoz, M.E.S., Giovanni, R., Siqueira, M.F., Sutton, T., Brewer, P., Pereira, R.S, Canhos, D.A.L. \& Canhos, V.P. (2009) OpenModeller: a generic approach to species' potential distribution modeling. GeoInformatica, 15: 111-125.

Neves, F.S., Queiroz-Dantas, K.S., Rocha, W.D. \& Delabie, J.H.C. (2013). Ants of three adjacent habitats of a transition region between the cerrado and caatinga biomes: the effects of heterogeneity and variation in canopy cover. Neotropical Entomology, 42: 258-268. doi: 10.1007/s13744-013-0123-7

Peterson, A.T., Soberón, J. \& Sánchez-Cordero, V. (1999). Conservatism of ecological niches in evolutionary time. Science, 285: 1265-1267.

Phillips, S.J. \& Dudik, M. (2008). Modeling of species distributions with MaxEnt: new extensions and a comprehensive evaluation. Ecography, 31: 161-175. doi: 10.1111/j.0906-7590.2008.5203.

Qin, Z., Zhang, J., DiTommaso, A., Wang, Rui-long. \& Wu, Rui-shan. (2015). Predicting invasions of Wedelia trilobata (L.) Hitchc. with Maxent and GARP models Journal of Plant Research, 128: 763-775. doi: 10.1007/s10265-015-0738-3

Raimundo, R.L.G., Fonseca, R.L., Schachetti-Pereira, R., Peterson, A.T. \& Lewinsohn, T.M. (2007). Native and exotic distributions of siamweed (Chromolaena odorata) modeled using the genetic algorithm for rule-set production. Weed Science, 55: 41-48. doi: 10.1614/WS-06-083.1

Ribeiro, M.C., Metzger, J.P., Martensen, A.C., Ponzoni, F.J. \& Hirota, M.M. (2009) The Brazilian Atlantic Forest: how much is left, and how is the remaining forest distributed? Implications for conservation. Biological Conservation, 42: 1141-1153. doi: j110.1016/jbiocon2009.02021
Ribeiro, M.C., Martensen, A.C., Metzger, J.P., Tabarelli, M., Scarano, F.R. \& Fortin, M.J. (2011). The Brazilian Atlantic Forest: a shrinking biodiversity hotspot. In: Zachos, F.E. \& Habel, J.C. (Eds.), Biodiversity Hotspots. Springer, Heidelberg, p. 405-434. doi: 10.1590/S1519-69842010000400002

Santos, R.J., Koch, E.B.A., Leite, C.M.P., Porto, T.J. \& Delabie, J.H.C. (2017). An assessment of leaf-litter and epigaeic ants (Hymenoptera: Formicidae) living in different landscapes of the Atlantic Forest Biome in the State of Bahia, Brazil. Journal of Insect Biodiversity, 5: 1-19.

Silva, E.M. \& Delabie, J.H.C. (2014). Formicidae (Hymenoptera) do Semiárido. pp. 203-213. In: Bravo F. \& Calor A. (Orgs.), Artrópodes do Semiárido, Biodiversidade e Conservação. Feira de Santana: Printmídia. 298 pp. ISBN: 978-85-62465-16-1

Solar, R., Chaul, J.C.M., Maues, M.M. \& Schoereder, J.H. (2016). A quantitative baseline of ants and orchid bees in human-modified Amazonian landscapes in Paragominas, PA, Brazil. Socioiology, 63: 925-940. doi: 10.13102/sociobiology. v63i3.1052

SOS Mata Atlântica/INPE-Instituto Nacional de Pesquisas Espaciais (2017). Atlas dos remanescentes florestais da Mata Atlântica - Período 2015-2016. https://www.sosma.org.br/ projeto/atlas-da-mata-atlantica/dados-mais-recentes/

Ulysséa, M. A. \& Brandão, C. R. (2013). Ant species (Hymenoptera, Formicidae) from the seasonally dry tropical forest of northeastern Brazil: a compilation from field surveys in Bahia and literature records. Revista Brasileira de Entomologia, 57: 217-224. doi: 10.1590/S0085-56262013005000002

Vasconcelos, H.L., Maravalhas, J.B., Feitosa, R.M., Pacheco, R., Neves, K.C., Andersen, A.N. (2018). Neotropical savanna ants show a reversed latitudinal gradient of species richness, with climatic drivers reflecting the forest origin of the fauna. Journal of Biogeography, 45: 248-258. doi: 10.1111/jbi.13113

Wild, A. \& Cuezzo, F. (2006). Rediscovery of a fossil dolichoderine ant lineage (Hymenoptera: Formicidae: Dolichoderinae) and a description of a new genus from South America. Zootaxa, 1142: 57-68. doi: 10.13102/sociobiology. v62i2.296-299

Wilson, E. O. (1985). Ants of the Dominican amber 3. The subfamily Dolichoderine. Psyche, 92: 17-37. doi: 10.1155/ 1985/20969.

Wisz, M.S., Hijmans, R., Li, J., Peterson, A.T., Graham, C.H. \& Guisan, A. (2008). Effects of sample size on the performance of species distribution models. Diversity and Distributions, 14: 763-773. doi: 10.1111/j.1472-4642.2008.00482.x

Young C.E.F (2003) Socioeconomic causes of deforestation in the Atlantic forest of Brazil. In: Galindo-Leal, C. \& Câmara, I.G (Eds.) The Atlantic Forest of South America: Biodiversity Status, Threat and Outlook. Island Press, Conservation International, Washington, p. 103-117. 